Article

\title{
Automatic Faulted Feeder Section Location and Isolation Method for Power Distribution Systems Considering the Change of Topology
}

\author{
Kongming Sun, Qing Chen * and Pu Zhao \\ Key Laboratory of Power System Intelligent Dispatch and Control, Shandong University, Ministry of Education, \\ Jinan 250061, China; skming.2008@163.com (K.S.); zhaopu106@163.com (P.Z.) \\ * Correspondence: qchen@sdu.edu.cn; Tel.: +86-531-8839-2403 \\ Academic Editor: Gianfranco Chicco \\ Received: 30 March 2017; Accepted: 18 July 2017; Published: 25 July 2017
}

\begin{abstract}
The increasing use of modern measuring devices, such as Feeder Terminal Units (FTUs), on power networks can provide multiple types of information for fault location on distribution systems. Using these devices, in this paper, a novel automatic matrix-based algorithm for the identification and isolation of faulted feeder sections on distribution systems is proposed. The algorithm works in two stages: the first stage automatically identifies the radial feeders that make up the whole system and represents the feeders' topology in matrix form; and the second stage automatically identifies the faulted section of the identified feeder and opens the relevant switches to isolate it. The algorithm can be applied to single and multiple faults, as it operates using measuring device information and detecting the status of switch devices. It does not require any electrical parameters and it is not affected by the fault type or fault resistance. The algorithm was thoroughly tested using a large distribution system and was found to efficiently identify and isolate the faulted feeder section in each case.
\end{abstract}

Keywords: power distribution system; faulted location; fault isolation; matrix-based method; topology identification

\section{Introduction}

Traditionally, fault location on distribution systems was a particularly difficult task. It is well known that around $80 \%$ of faults occur on distribution systems [1]. Thus, to locate the faulted feeder section fast and automatically in distribution systems is an important way to improve the reliability of power supply and to reduce energy losses. Before, various fault location algorithms (FLAs) on distribution systems have been proposed. Some methods have used simple but time-consuming visual inspection to locate the fault [2]. Other fault location algorithms that have been proposed include impedance based methods [3-8], travelling-wave based methods [9-11], minimum fault reactance methods [12,13], voltage-sag based methods [14-17], knowledge based methods [18-20], and multi-agent approaches [21,22]. However, due to the relatively complex nature of distribution systems, each of these methods has some disadvantages. Impedance based methods may have multiple estimation problems. Travelling-wave based methods cannot be used on inhomogeneous feeders as the surge impedance changes drastically between the overhead lines and underground cables, and errors in the detection and timing of the waves can result in large inaccuracies in the location of the fault. Voltage-sag based methods determine the fault location by comparing measured fault data with pre-fault data.

Most of these fault location algorithms assume that the system is radial and that its exact configuration is known in advance. However, the topology of distribution system changes frequently 
for the purpose of reconfiguration to reduce energy losses [23]. This brings difficulties to these methods. Besides, the aforementioned FLAs tend to locate the exact point of the fault on the feeder section from some set reference point. However, to isolate the fault and reduce energy losses, it is sufficient to just identify the faulted section of the feeder. This is because, even if the fault point can be located exactly, the whole faulted section should still be isolated to isolate the fault. Locating a faulted section is easier than locating the exact fault point.

The most similar work in the literature to the algorithm proposed in this paper is presented in [24]. That method shows good efficiency when identifying the faulted section of a radial feeder, but it does not automatically recognize the radial feeders from the whole system. In addition, once the configuration of the target radial network is changed, the matrix used in [24] will be reformed, and the authors do not mention how to form it automatically. These two aspects may reduce the efficiency of the method. The proposed method overcomes these two difficulties. It can not only automatically identify the radial networks from the whole system, but can also transform these networks into incidence matrices. Thus, manpower and outage time can be reduced.

Though methods to identify distribution system topologies have been proposed [25-28], they do not mention how to transform the network into mathematical forms that can be used for faulted section location. Each method works off-line, meaning that they cannot automatically update the system configuration and identify radial feeders in real time.

In recent years, in many countries, such as China, measuring devices (MDs) are becomingly increasing commonplace on modern distribution systems. Each switch (tie switch or sectionalizing switch) is matched with a FTU when it is delivered. Such MDs can measure the voltages and currents at their point of installation and detect the status of local switches and circuit breakers (CBs) and upload the obtained data to a control center. Each time the status of a switch or CB changes (i.e., opens or closes), the MD will send the new status information to the control center. Thus, the configuration of the distribution system is continuously updated in real-time. Similarly, should a fault occur, the MD will send fault information to the control center.

The information sent from the MDs to the control center is stored in a constantly updated database of the status of each switch and CB and any fault data. Based upon the information stored in such a database, a two-stage fault location and isolation algorithm for distribution systems is proposed.

The first stage of the proposed algorithm is initialized by status information and the second stage is initialized by fault information. Every time the status of a switch is changed (i.e., opened or closed), its MD will send a signal to the control center to update the database. The first stage of the proposed algorithm will identify the radial circuits in the distribution system, regardless of whether there is a fault or not. When complete, the identified radial circuits will be stored in matrix form in the control center. Should the configuration of the distribution system be changed, then the first stage will be automatically repeated so that the stored matrices always represent the latest network configuration.

When a fault occurs, the fault information uploaded to the control center by the MDs will start the second stage of the proposed algorithm. The matrices stored in the control center in the first stage and the fault information are then used to identify the faulted feeder section and the switches that should be opened to isolate the fault.

The only thing that needs to be done manually is to number all of the MDs and the feeder sections to form an initial network description matrix. The matrix has a good sparse characteristic. Though the size of the matrix may be large if it is used to describe a distribution system with numerous MDs and feeder sections, it will not be an onerous task to form it due to the sparse characteristic of the matrix. Once that matrix is established, it will always be available so long as the system is not reconstructed or expanded.

Since the data used by the algorithm are constantly updated, the algorithm automatically identifies and isolates the relevant feeder should a fault occur on the distribution system. As the algorithm does not use any physical or electrical parameters of the feeders, it is not affected by reconfigurations of the distribution system; it is not affected by the fault type or fault/arc resistance [29-33]; and it can be 
used on inhomogeneous feeders consisting of sections of both overhead line and underground cable. This represents a significant advance on the state of the art in distribution system fault location.

The three novelties of this method are as follows:

- Novelty 1: The method can automatically recognize the radial networks from the whole distribution systems and transform them into matrix form. This is novel because other methods can only do one of the two parts. Reference [24] can transform the radial network into matrix, but the radial network must be given first. In addition, the method does not give an automatic method to form the matrix. In distribution systems, for the frequent changing of its topology, it is an onerous task to do the two parts manually. The algorithms proposed in [22-25] can only recognize the topology of the network. Thus, the novel algorithm proposed in this paper is that it can dramatically reduce the required manpower and is not affected by the changes of topology.

- Novelty 2: The method is applicable for multiple faults. It is novel because other methods such as [3-13] do not consider multiple faults. In addition, the authors of [24] state that their method will have limitations when locating multiple faults. Besides, many other methods, such as impedance-based methods [3-8] have multi-estimation problem, which should be solved using other skills. The new proposed method does not have this problem.

- Novelty 3: The method can automatically identify the switches that should be opened to isolate the fault after it is located. Methods such as electrical-parameter-based methods [3-17,24] can determine the fault point or faulted section only, but cannot give the switches that should be opened to isolate the fault. The importance of this is that there is no need to adopt other methods to isolate the fault. Thus, fault location and isolation are combined in the proposed method.

\section{Identification of the Radial Networks}

In this section, a method of identifying radial networks from the whole distribution system in question is proposed. The distribution system shown in Figure 1 is used to demonstrate how the proposed method is derived. The network is composed of three main feeders, three CBs, and 17 sectionalizing-switches. Each of the switching devices is monitored by a MD. The switching devices divide the system into 20 feeder sections, which are marked in dotted ellipses. All MDs and feeder sections are numbered.

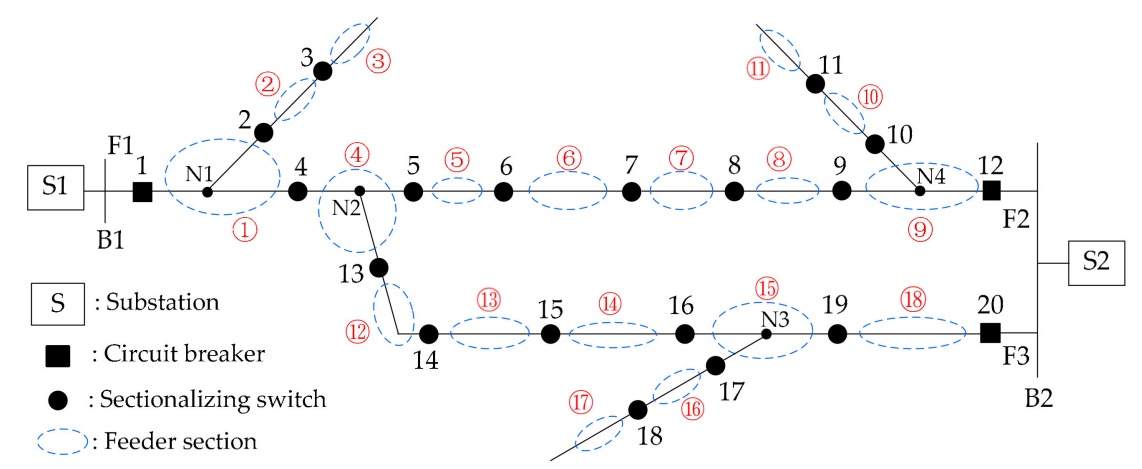

Figure 1. Single line diagram of a simple distribution system with all the switches closed.

\subsection{Form the Network Description Matrix}

In this section, a network description matrix, $\mathbf{M}_{\mathrm{o}}$, is derived to show the adjacency relationship between MDs and feeder sections. For a system with $m$ feeder sections and $n$ MDs, the dimensions of $\mathbf{M}_{\mathrm{o}}$ are $m$ by $n$. Each column of $\mathbf{M}_{\mathrm{o}}$ represents a MD and each row represents a feeder section. Information is stored in $\mathbf{M}_{\mathrm{o}}$ in binary form, i.e., 1 or 0 with 1 meaning that the $\mathrm{MD}$ is adjacent to the feeder section, and 0 meaning that the MD is not adjacent to the feeder section. Taking feeder section (4) in Figure 1 as an example, MDs 4, 5 and 13 are all adjacent to it, while MD 2 is not. 
Initially, the system is assumed to operate in a closed-loop configuration, as shown in Figure 1, with all switches closed. Using the above method, the description matrix for the system in Figure 1 can be expressed as follows:

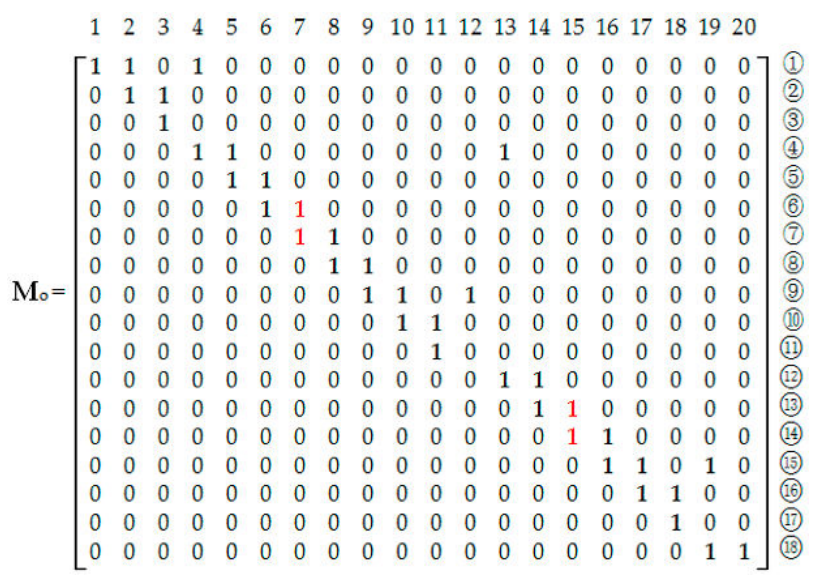

\subsection{Determine the Sets of MDs and Feeder Sections}

Here, a state vector $\mathbf{s}$, that shows the status of all the MDs, is defined. The dimension of this vector equals the number of MDs. Information is stored in this vector in binary form: 1 signifies that the switch the MD monitors is closed, while 0 signifies that it is open. The information for this vector can be obtained from the database in the control center.

Under normal operating conditions, the network in Figure 1 would be opened. Here it is assumed that Switches 7 and 15 are opened to split the system into three radial circuits. Then, the state vector will be:

$$
\mathbf{s}=[11111101111111011111]^{\mathrm{T}}
$$

It is stipulated that if a switch is opened, it will not be adjacent to any feeder sections. Under this stipulation, the original description matrix $\mathbf{M}_{\mathrm{O}}$ cannot describe the real operating condition of the system and it must be modified accordingly. The modification algorithm is shown in Figure 2. The main idea of the algorithm is to set the " 1 " elements in the columns corresponding to the opened switches to " 0 ". In the algorithm, $k, j$ are the iteration indices. $s(k)$ is the $k$ th element of $\mathbf{s}, m(j, k)$ is the element at the $j$ th row and $k$ th column of $\mathbf{M}$.

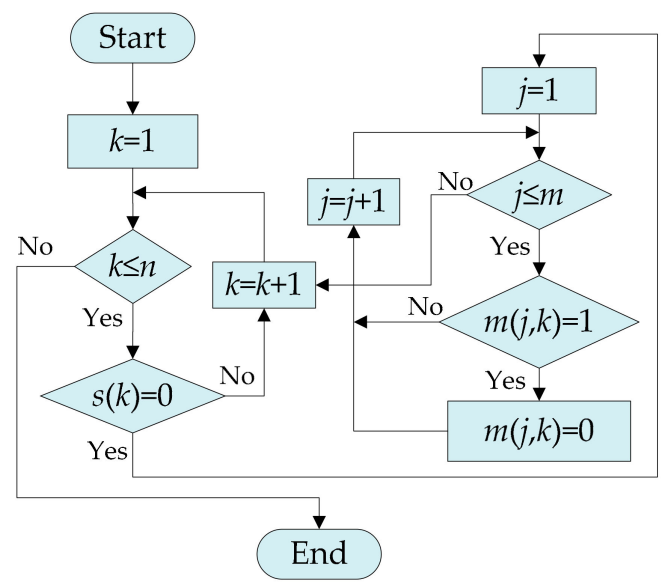

Figure 2. Modification of the original network description matrix $\mathbf{M}_{\mathrm{O}}$. 
By performing this algorithm, the elements of matrix $\mathbf{M}_{\mathrm{o}}(6,7),(7,7),(13,15)$ and $(14,15)$ which are marked in red in $\mathbf{M}_{\mathrm{o}}$ will be changed to 0 . The modified network description matrix is presented as $\mathbf{M}$.

Distribution systems are normally operated as a number of radial circuits. Generally, the number of radial circuits is equal to the number of main feeders, except when the feeder is disconnected from the substation and powered by another feeder. Each radial circuit comprises a set of MDs and a set of feeder sections. To identify the exact topologies of the circuits, these sets must be determined. Figure 3 depicts the proposed algorithm that is used to search the modified $\mathbf{M}$ to determine the MD sets and feeder section sets in detail. It can be explained in the following steps: (i) determine the number of MD set and feeder section set according to the number of main feeders (or the number of CBs); (ii) set the ID of the $i$ th $\mathrm{CB}$ as the 1 th element of the $i$ th MD set; (iii) determine the elements belonging to the $i$ th MD set and the elements belonging to the $i$ th feeder section set according to the modified network description matrix $\mathbf{M}$; and (iv) repeat Steps (ii) and (iii) until all the MDs and feeder sections are traversed. In the algorithm, vector $\mathbf{b}$ represents the serial numbers of the CBs. $d_{b}$ is the dimension of $\mathbf{b}$. Vector $\mathbf{d}_{i}$ demotes the $i$ th MD set, and vector $\mathbf{l}_{i}$ means the $i$ th feeder section set. $d_{d i}$ is the dimension of $\mathbf{d}_{i}$ and $d_{l i}$ is the dimension of $\mathbf{1}_{i}$. Their initial values are all 0 . A MD will be loaded into $\mathbf{d}_{i}$ when it is determined to belong to the vector and $d_{d i}$ will be incremented by $1 . e, i, j, k, p, q$ and $t$ are the iteration indices. Other symbols are the same as the previous statements.

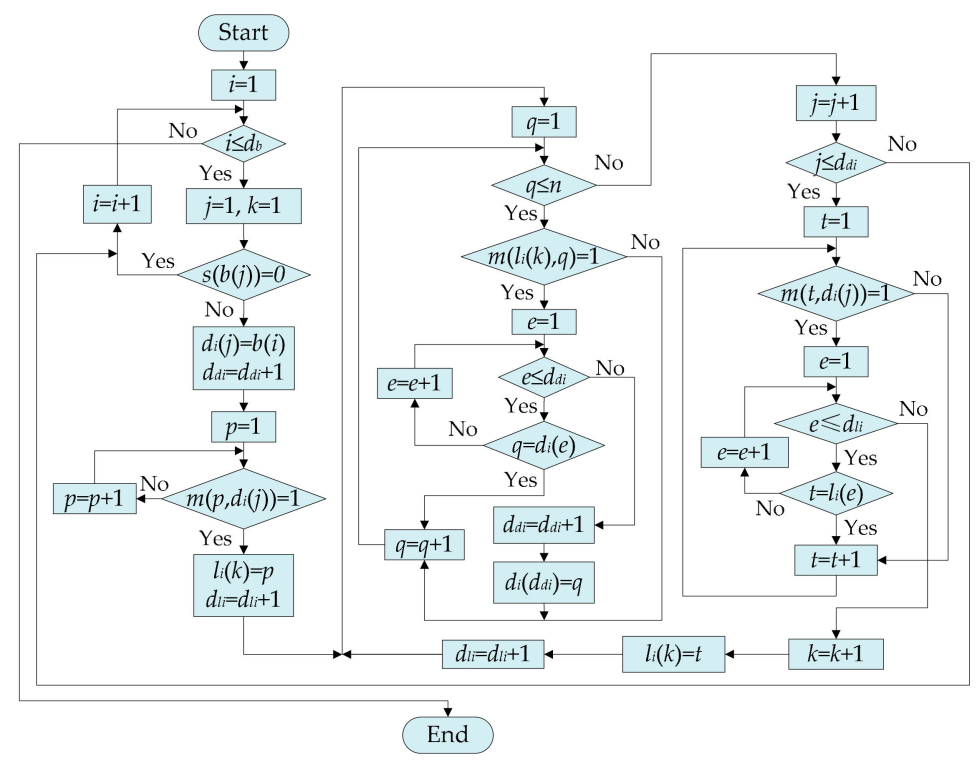

Figure 3. Algorithm to determine the MD sets and feeder section sets.

By using the algorithm on the modified network description matrix $\mathbf{M}$, the three MD sets and three feeder section sets are obtained as:

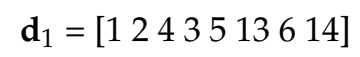

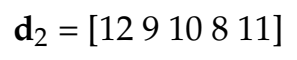

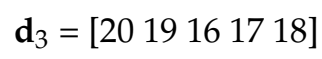

$$
\begin{aligned}
& \mathbf{l}_{1}=\text { [(1) (2) (4) (3) (5) (12) (6) (13] } \\
& \mathbf{l}_{2}=[\text { [(9) (8) (11) (7) (11)] } \\
& \mathbf{1}_{3}=\text { [(18)(15) (14) (16)(17)] }
\end{aligned}
$$




\subsection{Determine the Radial Networks}

In this section, an algorithm to identify the radial networks is developed. The algorithm is based on the MD sets and feeder section sets formed in Section 2.2. The identified networks are not represented graphically, but in the form of matrices which can be used for faulted feeder section location and isolation. Matrix $\mathbf{R}_{i}$ whose dimension is $d_{l i}$ by $d_{d i}$ is used to represent the $i$ th radial network. The algorithm is detailed in Figure 4. It can be explained in the following steps: (i) determine the number of radial distribution networks according to the number of main feeders; (ii) set the $i$ th MD set as the column of the $i$ th radial network $\mathbf{R}_{i}$ and the $i$ th feeder section set as the row; (iii) determine the elements of the $\mathbf{R}_{i}$ according to the modified network description matrix $\mathbf{M}$; and (iv) repeat Steps (ii) and (iii) until all the radial networks are determined. In the algorithm, $i, j, k, t$ and $p$ are the iteration indices. Other symbols are the same as the previous statements.

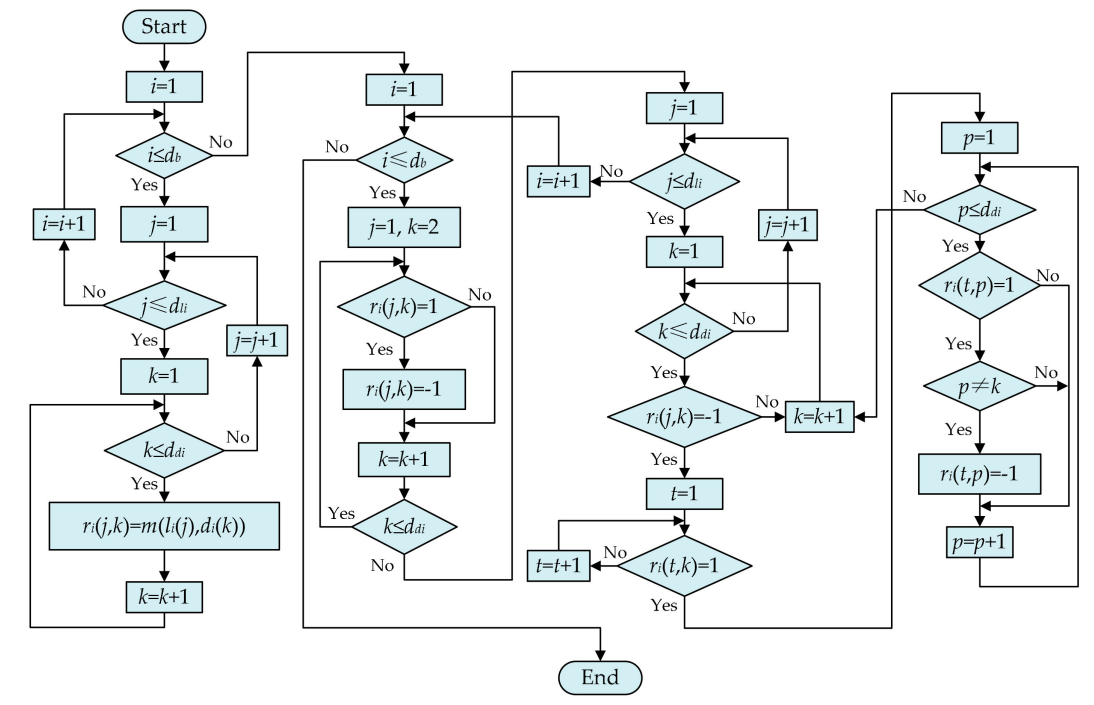

Figure 4. Algorithm to form the matrices of the radial networks.

By using the algorithm on the example system from Figure 1, the radial networks are identified and represented as (9)-(11). The three matrices, $\mathbf{R}_{1}, \mathbf{R}_{2}$, and $\mathbf{R}_{3}$, describe the topology of the radial networks. There are three elements in these matrices $(1,0$ and -1$): r_{i}(j, k)=1$ means the current flows from the $d_{i}(k)$ th MD to $l_{i}(j)$ th feeder section; $r_{i}(j, k)=-1$ means the current flows from the $l_{i}(j)$ th feeder section to $d_{i}(k)$ th MD; and 0 signifies that there is no current flow directly between the MD and feeder section related to this item. The matrix shows not only the topological relationship between MDs and feeder sections but also the direction of current flow in the network. Here, the direction of the current flowing in a line section is from the source end to the receiving end.

The three steps in this section constitute the first stage of the proposed algorithm, which is a method to identify the radial networks from the whole distribution system. The developed matrices will be used in the next section for faulted feeder section identification and isolation.

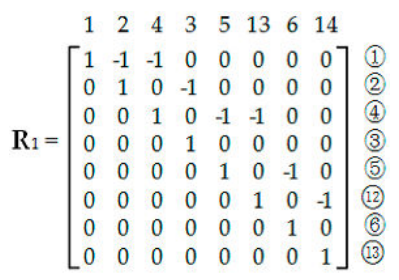




$$
\mathbf{R}_{3}=\left[\begin{array}{ccccc}
20 & 19 & 16 & 17 & 18 \\
0 & -1 & 0 & 0 & 0 \\
0 & 0 & -1 & -1 & 0 \\
0 & 0 & 0 & 1 & -1 \\
0 & 0 & 0 & 0 & 1
\end{array}\right] \text { (17) (17) }
$$

\section{Faulted Feeder Section Location and Isolation}

When a fault occurs, the MDs on the network will send fault signals to the control center. When the control center has received the fault information, the second stage of the proposed algorithm is initialized. The matrices stored in the first stage are used along with the fault data by the algorithm to identify and isolate the faulted feeder section.

A short time delay is required before updating the database when the status information is uploaded to the control center. This is because when a fault occurs, the CB at the very beginning of the feeder may trip to cut off the fault current, meaning that the configuration of the network will be changed. The time delay is to ensure that the radial networks formed in the first stage represent the network before the fault occurred.

\subsection{Form the Fault Information Vector $v_{i}$ for Each Sub-Network}

First, a fault information vector $\mathbf{v}$ that stores fault information from all of the MDs is defined. The fault information is stored in the vector in binary form: 1 signifies that the MD has detected a fault current, while 0 signifies that no fault current has been detected.

Taking Figure 5 as an example, when there is a fault in feeder section (5), MDs 1, 4 and 5 will be triggered. They then upload the fault information to the control center to update the database. Using the fault data thus stored in the database, the fault information vector can be obtained as:

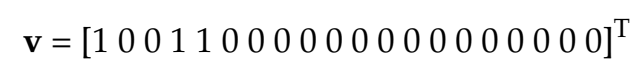

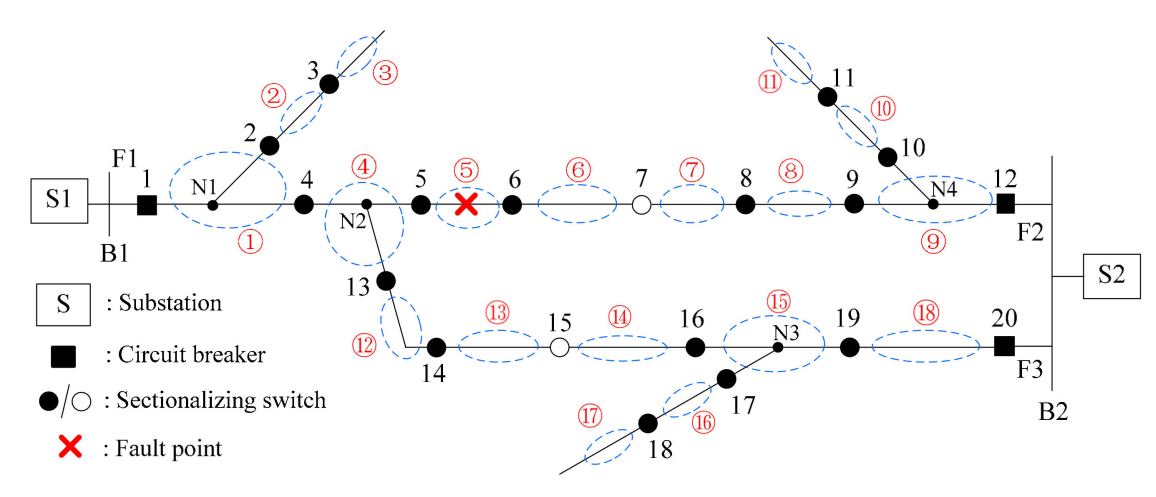

Figure 5. A fault example.

Next, the fault information vector $\mathbf{v}_{\mathbf{i}}$ for each identified radial network is formed using the following six-step algorithm:

Step 1: Set the start value of $i$ as 1;

Step 2: If $i$ is bigger than $d_{b}$, then stop the procedure; otherwise go to the next step; 
Step 3: Set the start value of $j$ as 1;

Step 4: If $j \leq d_{d i}$, then go to the next step, else go to Sep 2 with $i=i+1$;

Step 5: Assign the value of $v\left(d_{i}(j)\right)$ to $v_{i}(j)$;

Step 6: Increase the iteration index: $j=j+1$, then go to Step 4 .

The dimension of $\mathbf{v}_{i}$ is equal to $d_{d i}$, and the order of the MDs in the vector is the same as those in $\mathbf{d}_{i}$. For the case shown in Figure 5, the algorithm gives the three following fault information vectors:

$$
\begin{aligned}
& \mathbf{v}_{1}=\left[\begin{array}{lllllll}
1 & 0 & 1 & 0 & 1 & 0 & 0
\end{array}\right]^{\mathrm{T}} \\
& \mathbf{v}_{2}=\left[\begin{array}{lllll}
0 & 0 & 0 & 0 & 0
\end{array}\right]^{\mathrm{T}} \\
& \mathbf{v}_{3}=\left[\begin{array}{llll}
0 & 0 & 0 & 0
\end{array}\right]^{\mathrm{T}}
\end{aligned}
$$

\subsection{Determine the Faulted Feeder Section}

In this Section, a fault indicating vector $\mathbf{f}_{i}$ that identifies the faulted feeder section in the $i$ th radial circuit is defined. The vector is calculated using Equation (16). The non-zero element in $\mathbf{f}_{i}$ corresponds to the faulted feeder section. The indices of $\mathbf{f}_{i}$ are the same as those of $\mathbf{1}_{i}$.

$$
\mathbf{f}_{i}=\mathbf{R}_{i} \cdot \mathbf{v}_{i}
$$

For the operating conditions and fault example shown in Figure 5, the three fault indication vectors are calculated as:

$$
\begin{aligned}
& \mathbf{f}_{1}=\left[\begin{array}{lllllll}
0 & 0 & 0 & 0 & 1 & 0 & 0
\end{array}\right]^{\mathrm{T}} \\
& \mathbf{f}_{2}=\left[\begin{array}{lllll}
0 & 0 & 0 & 0 & 0
\end{array}\right]^{\mathrm{T}}
\end{aligned}
$$

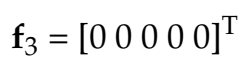

Although it is easy to manually identify feeder section $l_{1}(5)$ as the faulted section from the fault indication vectors, an iterative algorithm must be developed to automatically identify it:

Step 1: Set the start value of $i$ as 1;

Step 2: If $i>d_{b}$, then stop the procedure; otherwise go to the next step;

Step 3: Set the start value of $k$ as 1;

Step 4: If $k>d_{l i}$, then go to Step 2 with $i=i+1$; else go to the next step;

Step 5: Check the value of $f_{i}(k)$. If $f_{i}(k) \neq 0$, the feeder section $l_{i}(k)$ is the faulted section, then go to Step 4 with $k=k+1$; otherwise go to Step 6;

Step 6: Increase the iteration index: $k=k+1$, then go to Step 4 .

\subsection{Isolation of the Faulted Feeder Section}

Once the faulted feeder section has been determined, the switches that should be opened to isolate the fault can be determined using the radial network description matrix $\mathbf{R}_{i}$ and fault indication vector $\mathbf{f}_{i}$. An algorithm to automatically determine which switches should be opened is presented in Figure 6 . The isolation principle is that, in matrix $\mathbf{R}_{i}$, the switches whose corresponding elements are non-zero in the row of the faulted feeder section should be opened. In the algorithm, $i, j$, and $k$ are the iteration indices, other symbols are the same as the previous statements.

For the example fault in Figure 5, the algorithm determines that Switches 5 and 6 should be opened. When the correct switches have been identified, the control center will open these switches remotely to isolate the fault. 


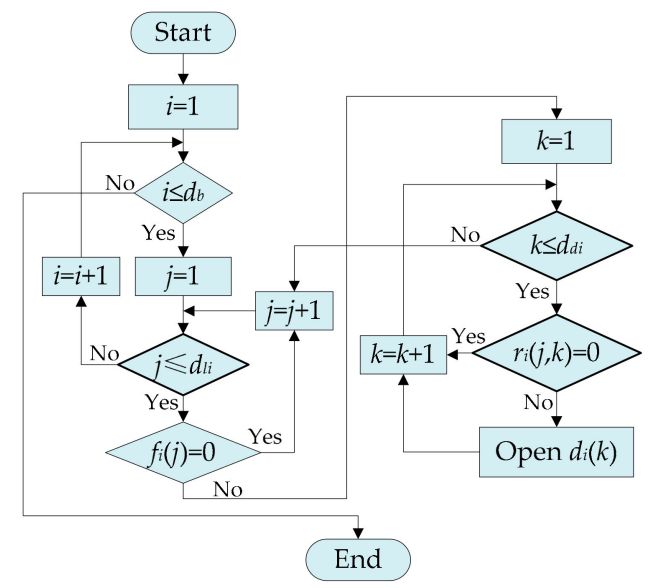

Figure 6. The algorithm for faulted feeder section isolation.

\section{Identification and Isolation of Multiple Faults}

There are three conditions for multiple faults:

(1) Multiple faults occur on different radial networks. For this condition, each fault will be located and isolated independently using the same method as for single faults.

(2) Multiple faults occur on different laterals in the same radial network. For example, for the two faults illustrated in Figure 7, the fault information vector for the faulted radial network under this condition is:

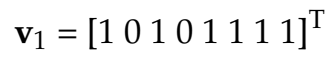

Substitute $\mathbf{R}_{1}$ and $\mathbf{v}_{1}$ into Equation (16) yields the fault indicating vector:

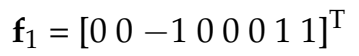

Note, that there is a negative element in $\mathbf{f}_{1}$, which is different from the fault indicating vector (17) for single faults. The existence of this non-zero element would lead to an incorrect identification of faulted feeder section. In order to make the method suitable for multiple faults, an algorithm to modify the fault information vector $\mathbf{v}_{i}$ is presented in Figure 8. Its main logic can be expressed as: If there are $n(n \geq 1)$ triggered FTUs at the very adjacent downstream of a triggered FTU, e.g., $\mathbf{d}_{\mathrm{i}}(k)$, then set the corresponding elements of these FTUs in $\mathbf{v}_{\mathbf{i}}$ as $\mathbf{v}_{i}(k) / n$. For the $i$ th radial network, the algorithm can be explained as the following steps: (i) set $k=1$; (ii) if $k>d_{d i}$, end the procedure; else, determine the number of triggered FTUs at the very adjacent downstream of the $\mathbf{d}_{\mathrm{i}}(k)$ th FTU, for example, $t$, if $t>0$, go to the next step, else, $k=k+1$, and repeat Step (ii); and (iii) set the corresponding elements of these triggered FTUs in $\mathbf{v}_{\mathrm{i}}$ as $\mathbf{v}_{i}(k) / t$; then go to Step (ii) with $k=k+1$. In the algorithm, $i, j, k, t, p$, and $q$ are the iteration indices, other symbols are the same as the previous statements. Once the $\mathbf{v}_{i}$ is formed, the algorithm in Figure 8 will be automatically applied to it irrespective of whether multiple faults have occurred.

By performing the algorithm in Figure 8 on the vector shown in Equation (20), the following fault information vector will be produced:

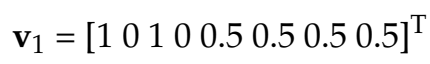

Then, by substituting Equations (9) and (22) into Equation (16) yields the new fault indication vector:

$$
\mathbf{f}_{1}=\left[\begin{array}{llllllll}
0 & 0 & 0 & 0 & 0 & 0 & 0.5 & 0.5
\end{array}\right]^{\mathrm{T}}
$$


The non-zero elements correspond to the faulted feeder sections. Using the isolation algorithm shown in Figure 6, Switches 6 and 14 would be opened to isolate the faulted feeder sections and there would be no need to determine whether it is a single fault or multiple faults.

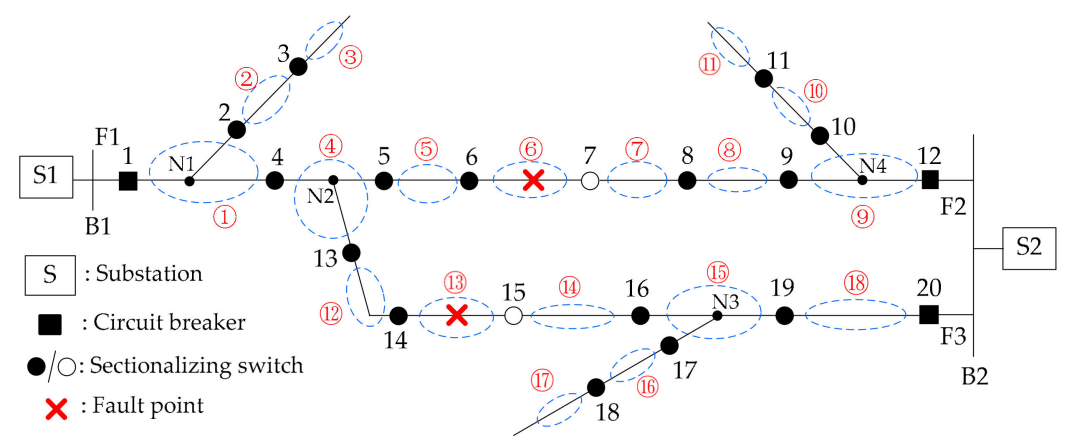

Figure 7. Multiple faults occurring on different branches in the same radial network.

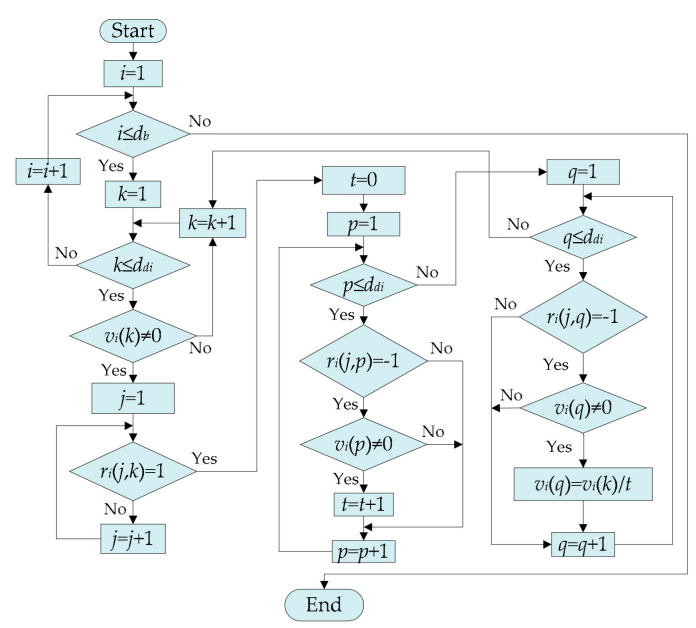

Figure 8. The algorithm to modify the $\mathbf{v}_{i}$.

(3) The proposed algorithm can also identify and isolate multiple faults occurring on different feeder sections on the same lateral. Suppose two faults occur in feeder sections (5) and (6), as shown in Figure 9. The path of the fault in (5) is overlapped by that in (6).

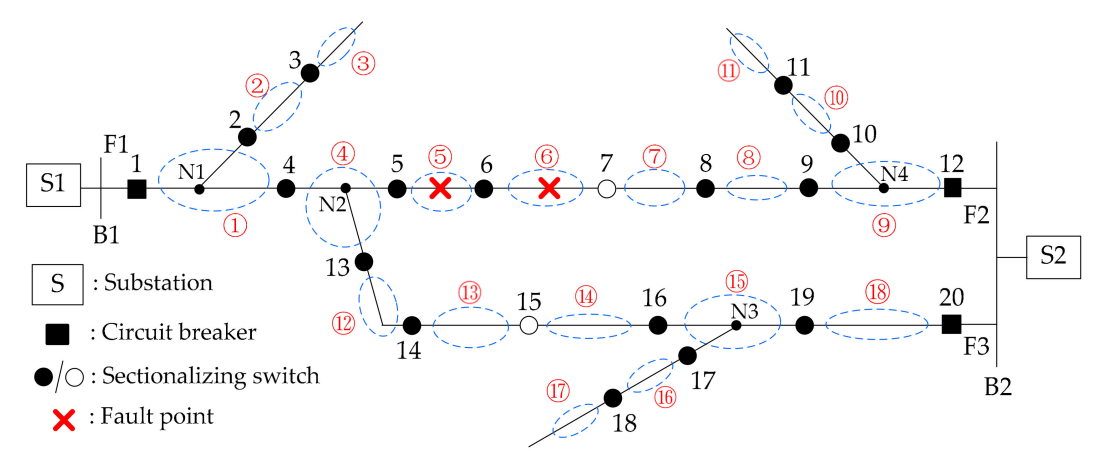

Figure 9. Multiple faults occur in the same lateral but different sections.

The fault information vector for the faulted radial network under this condition is:

$$
\mathbf{v}_{1}=\left[\begin{array}{llllllll}
1 & 0 & 1 & 0 & 1 & 0 & 1 & 0
\end{array}\right]^{\mathrm{T}}
$$


By substituting Equations (9) and (24) into Equation (16), the fault indication vector for this condition is calculated as:

$$
\mathbf{f}_{1}=\left[\begin{array}{llllllll}
0 & 0 & 0 & 0 & 0 & 0 & 1 & 0
\end{array}\right]^{\mathrm{T}}
$$

In this case, it seems that only the fault occurs in feeder section (6) has been located and isolated. However, when the fault is isolated and the CB is closed immediately to reconnect the healthy part of the network, the fault on feeder section (5) will cause the method to be triggered for a second time to locate and isolate the fault. By running the proposed algorithm twice, the two faults are located and isolated within a short time interval.

\section{Discussion of the Method}

\subsection{Operation with Parts of the Network Out of Service}

There may be the circumstances when parts of a distribution system are out of service, as illustrated in Figure 10. When this happens, the first stage of the proposed algorithm can still identify the powered radial circuits, and, if a fault occurs on them, it will be located and isolated using the proposed algorithm.

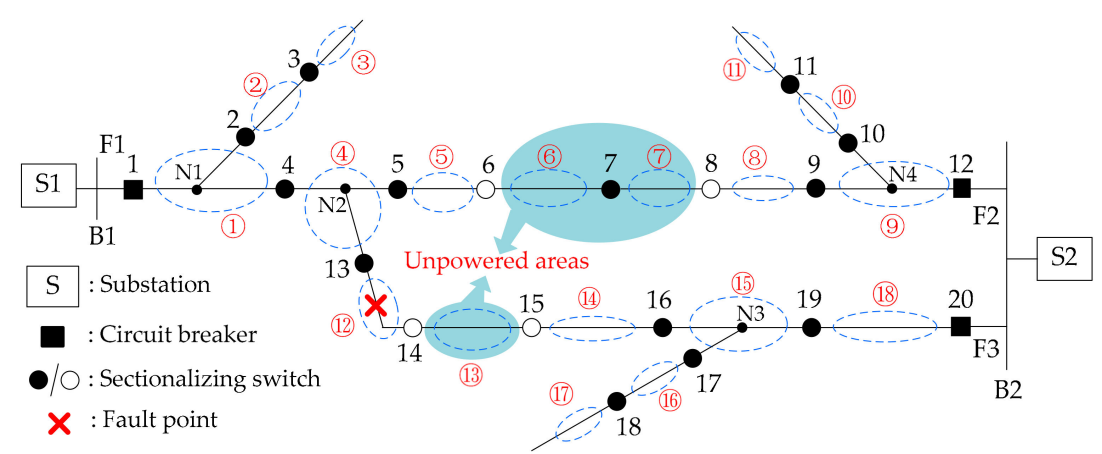

Figure 10. Operate with unpowered areas.

The state vector for the condition shown in Figure 10 is:

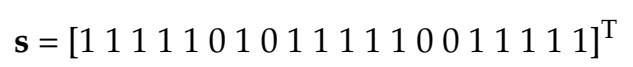

Using the topology identification algorithm proposed in Section 2, the radial networks can be obtained as:

$$
\begin{aligned}
& \mathbf{R}_{1}=\left[\begin{array}{rrrrrr}
1 & 2 & 4 & 3 & 5 & 13 \\
1 & -1 & -1 & 0 & 0 & 0 \\
0 & 1 & 0 & -1 & 0 & 0 \\
0 & 0 & 1 & 0 & -1 & -1 \\
0 & 0 & 0 & 1 & 0 & 0 \\
0 & 0 & 0 & 0 & 1 & 0 \\
0 & 0 & 0 & 0 & 0 & 1
\end{array}\right] \text { (1) (2) (3) } \\
& \begin{array}{llll}
12 & 9 & 10 & 11
\end{array} \\
& \mathbf{R}_{2}=\left[\begin{array}{cccc}
1 & -1 & -1 & 0 \\
0 & 1 & 0 & 0 \\
0 & 0 & 1 & -1 \\
0 & 0 & 0 & 1
\end{array}\right] \text { (1) (8) } \\
& 20191617 \quad 18 \\
& \mathbf{R}_{3}=\left[\begin{array}{ccccc}
1 & -1 & 0 & 0 & 0 \\
0 & 1 & -1 & -1 & 0 \\
0 & 0 & 1 & 0 & 0 \\
0 & 0 & 0 & 1 & -1 \\
0 & 0 & 0 & 0 & 1
\end{array}\right] \begin{array}{l}
(18) \\
(12) \\
(16)
\end{array}
\end{aligned}
$$


Supposing the fault occurred on feeder section (12), then the fault information vector will be:

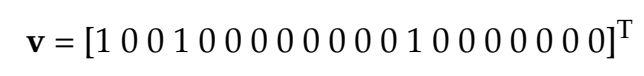

Using the faulted feeder section location method, the fault indication vector for the faulted radial network will be:

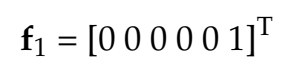

This result demonstrates that the proposed method can still be applied when several parts of the system are isolated. The method has a good robustness to the change of topology.

\subsection{Improvement of the Method Considering Fault Information Loss}

The proposed method has a high dependency on the completeness of the information from MDs. On the condition that some of the fault information is not reported back to the control center, the fault section may not be located correctly. In order to solve this problem, an iterative technique to inspect whether there is lost information developed in our previous published paper [34] is applied in this method. With this algorithm, the robustness of the method can be significantly improved.

\subsection{Cooperation of the Two Parts}

The flowchart of the whole method is presented in Figure 11. It can be seen that the method is composed of two parts. The first part is started by status information and the second part is initiated by fault information. Once the status information of a switch is changed, its MD will be triggered to upload the current status to the control center to update the database. When it is finished, the first part of the method will be started to identify the radial networks no matter whether there is a fault. After it is done, the identified networks represented in the form of matrix will be stored in the control center. Then, the method will be put into the idle state and wait for a fault to occur. When a fault occurs, the fault information uploaded to the control center will start the second part to call the already formed matrices and the fault information to recognize the faulted line section and the switches that should be switched off to isolate the fault.

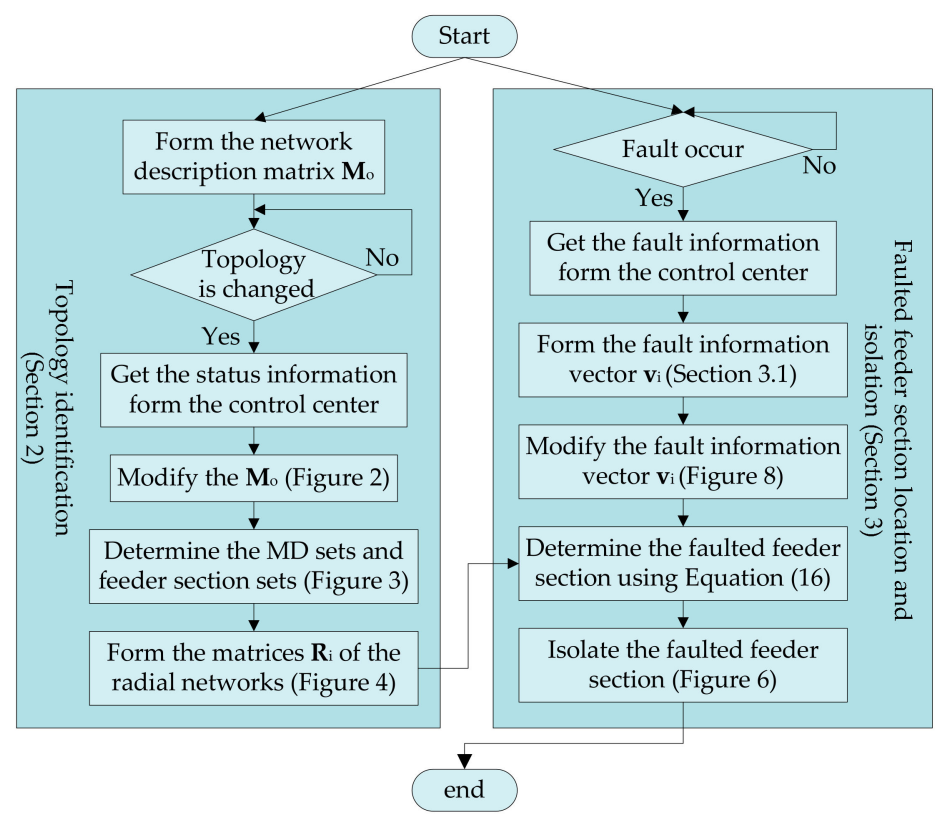

Figure 11. Flowchart of the proposed method. 


\section{Case Studies}

In order to test the performance of the proposed algorithm, various case studies have been undertaken. In this section, the cases that are studied using one relatively large distribution system as illustrated in Figure 12 is presented. The test system is an $11-\mathrm{kV}$ radial system having two substations, four feeders, 79 switches and 68 segments $[35,36]$.

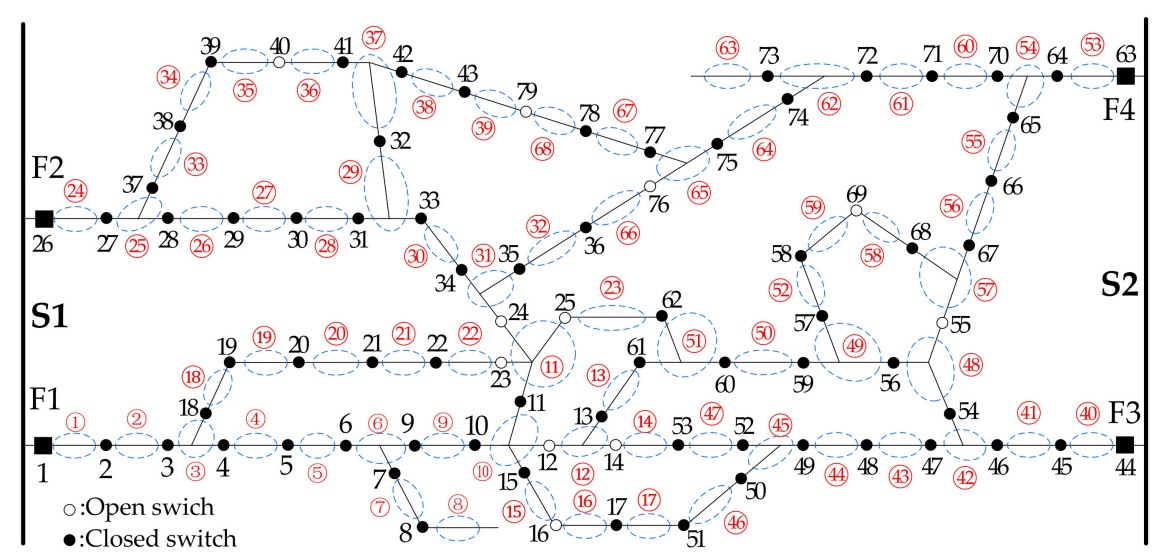

Figure 12. The test distribution system.

According to the definition in Section 2.1, the description matrix for the system can be expressed as that shown in the Appendix A.

Suppose the network operates under the condition shown in Figure 12 with Switches 12, 14, 16, $23,24,25,40,55,69,76$ and 79 open. Then, the state vector will be:

$$
\begin{gathered}
\mathbf{s}=[111111111110101011111100011111111111111 \\
0111111111111110111111111111101111110110]^{\mathrm{T}}
\end{gathered}
$$

Then, by performing the proposed network identification method, the four radial sub-networks that presented in matrices can be obtained as:

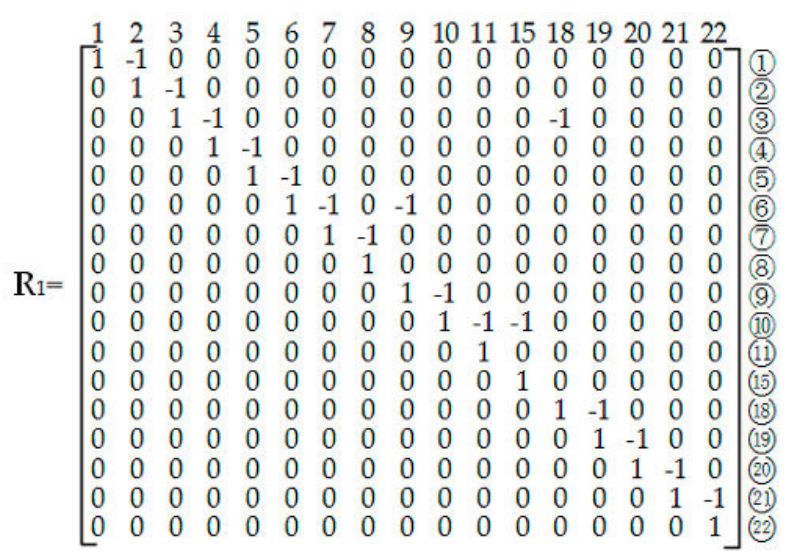



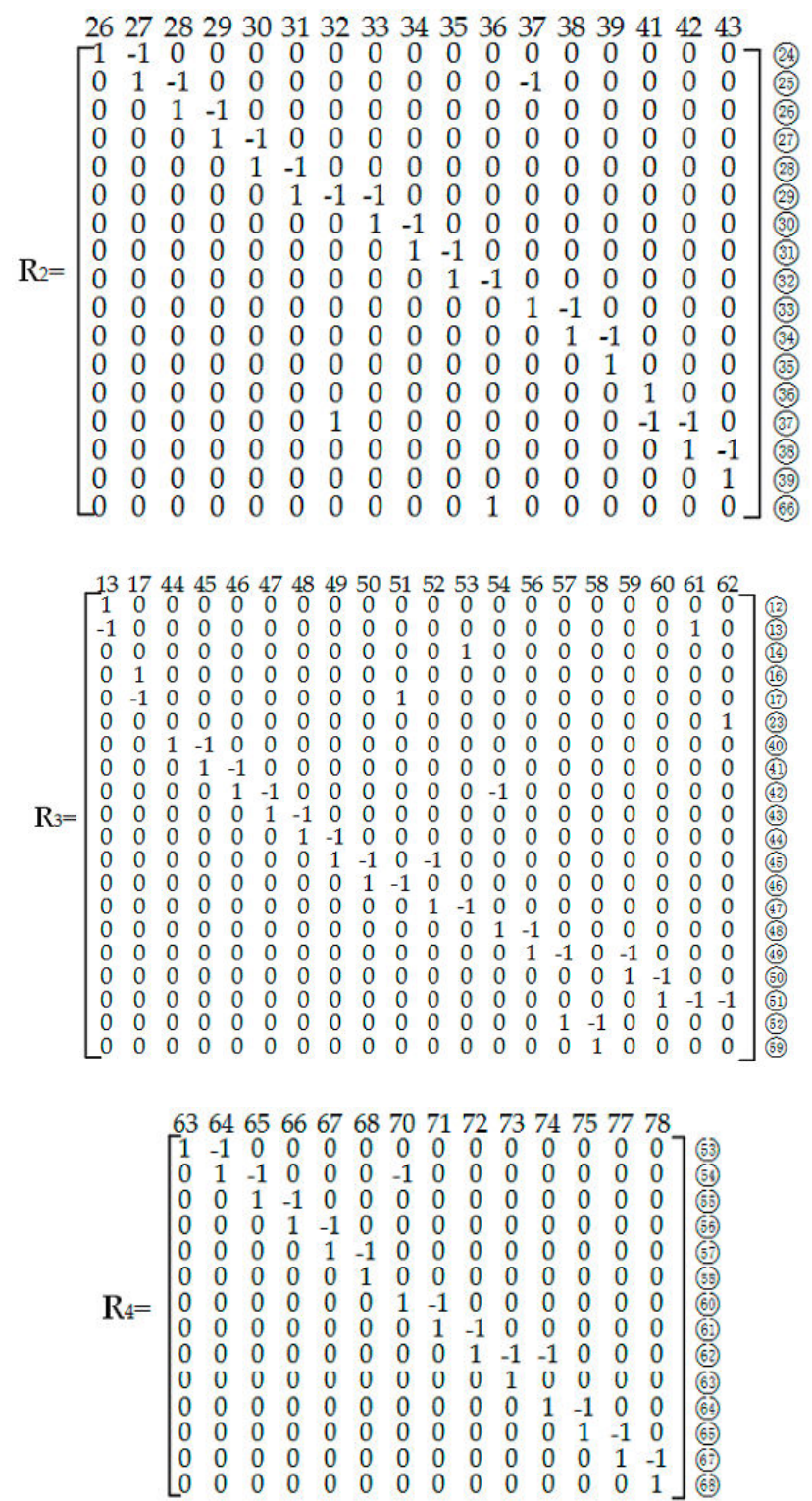

\subsection{Test Case 1: Single Fault in Each Radial Network}

In order to test the performance of the proposed method for single fault, it is supposed that each radial sub-network suffers from a fault. The fault points are demonstrated in Figure 13.

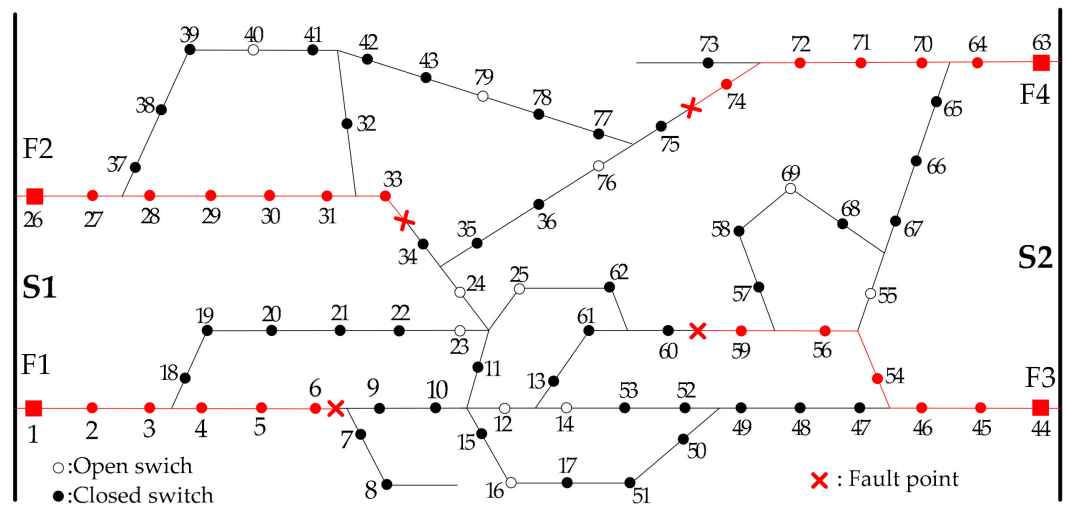

Figure 13. Single fault in each radial network. 
For this condition, the fault information vector for the whole system will be:

$$
\begin{aligned}
& \mathbf{v}=[1111110000000000000000000111111010000000 \\
& 000111000000010100100011000001110100000]^{\mathrm{T}}
\end{aligned}
$$

By applying the algorithm proposed in Section 3.1 on Equation (37), the fault information vector $\mathbf{v}_{\mathrm{i}}$ for each identified radial network can be obtained as:

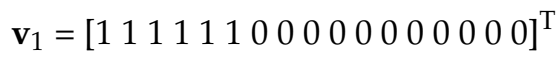

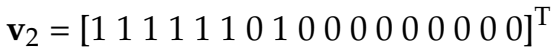

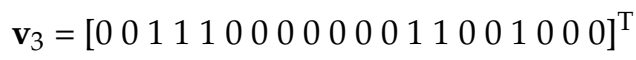

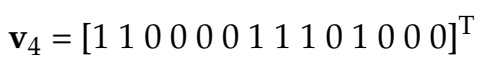

Then, using Equation (16), the fault indicating vectors for this case are calculated and written as:

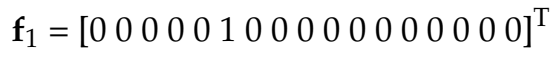

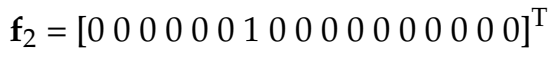

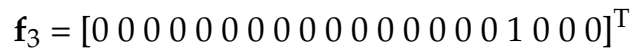

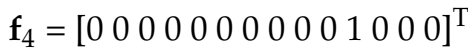

To determine the faulted feeder section, the automatic iterative algorithm proposed in Section 3.2 is applied to Equations (42)-(45). The result shows that the faulted feeder sections are (6), (30), (50) and (64). It is the same as what is illustrated in Figure 13.

Then, the switches that should be opened to isolate the faults can be determined using the algorithm shown in Figure 6. They are listed in Table 1.

Table 1. Switches to be opened to isolate the faults in sections (6), (30, (50) and (64).

\begin{tabular}{cccc}
\hline Fault Position & Open Switches & Fault Position & Open Switches \\
\hline (6) & 6,7 and 9 & 50 & 59 and 60 \\
$(30$ & 33 and 34 & (6) & 74 and 75 \\
\hline
\end{tabular}

For the condition shown in this case, the method can always be applicable, whether the faults occur simultaneously or not. This is because the formation of the fault information vector $\mathbf{v}_{\mathrm{i}}$ for the $i$ th radial network does not have any effect on the others.

\subsection{Test Case 2: Simultaneous Faults in Different Laterals in the Same Radial Network}

In this case, the system operates in a different condition with that presented in Figure 13. Switches $12,16,21,24,25,32,35,52,55,58$ and 79 are opened to maintain the radial constraint of the topology. The two faults, shown in Figure 14, occur in different laterals in feeder F2. 


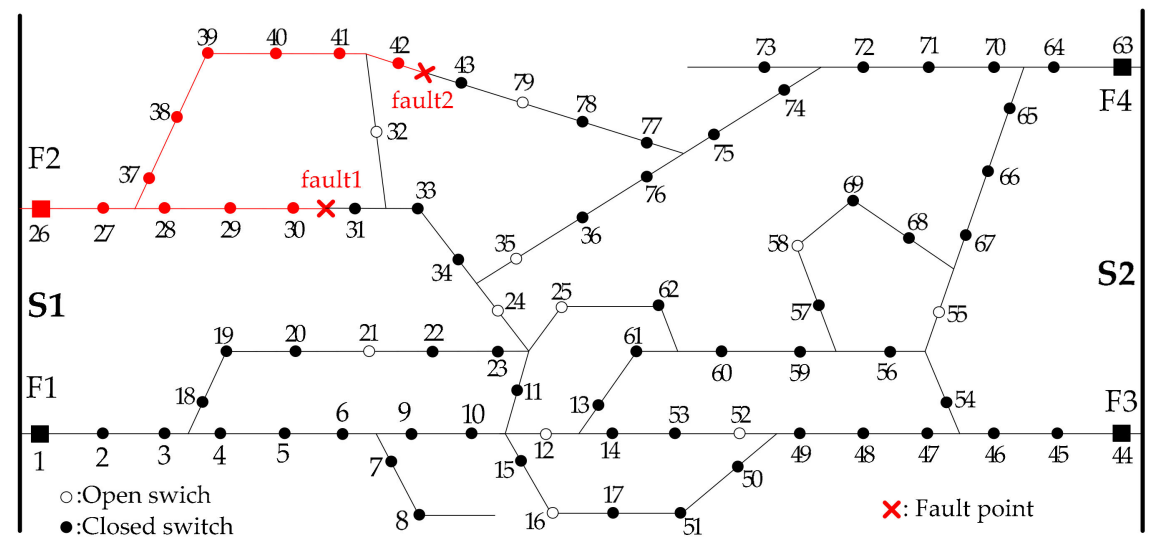

Figure 14. Simultaneous faults in different laterals in the same feeder F2.

The state vector for this operating condition is:

$$
\begin{gathered}
\mathbf{s}=[11111111111011101111011001111110110111 \\
11111111111110110110111111111111111111110]^{\mathrm{T}}
\end{gathered}
$$

By applying the topology identification method, the faulted radial network can be recognized and expressed as:

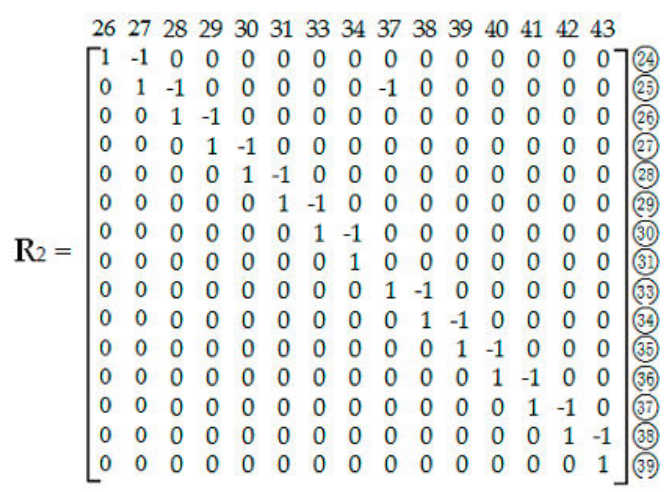

The fault information vector for this identified radial network is:

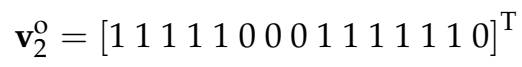

For the multiple faults, the fault information vector must be modified using the algorithm shown in Figure 8, and the new fault information vector will be:

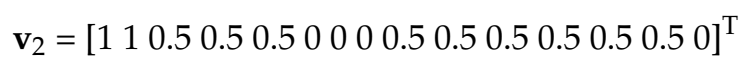

Then, the fault indicating vector for this case is calculated by substituting Equations (47) and (49) into Equation (16):

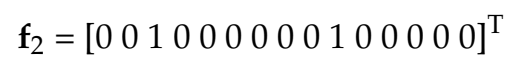

By applying the algorithm in Section 3.2 to this $\mathbf{f}_{2}$, it is determined that sections and are the faulted ones. It is the same as what is illustrated in Figure 14.

To isolate the two faults, the algorithm proposed in Figure 6 is conducted. Switches 30, 31, 42 and 43 should be opened. 


\subsection{Test Case 3: Simultaneous Faults in the Same Lateral}

In this case, Switches $11,12,13,15,22,25,31,35,55,57$ and 78 are opened to keep the radiality of the system. The two faults, illustrated in Figure 15, occur in the same lateral in feeder F1.

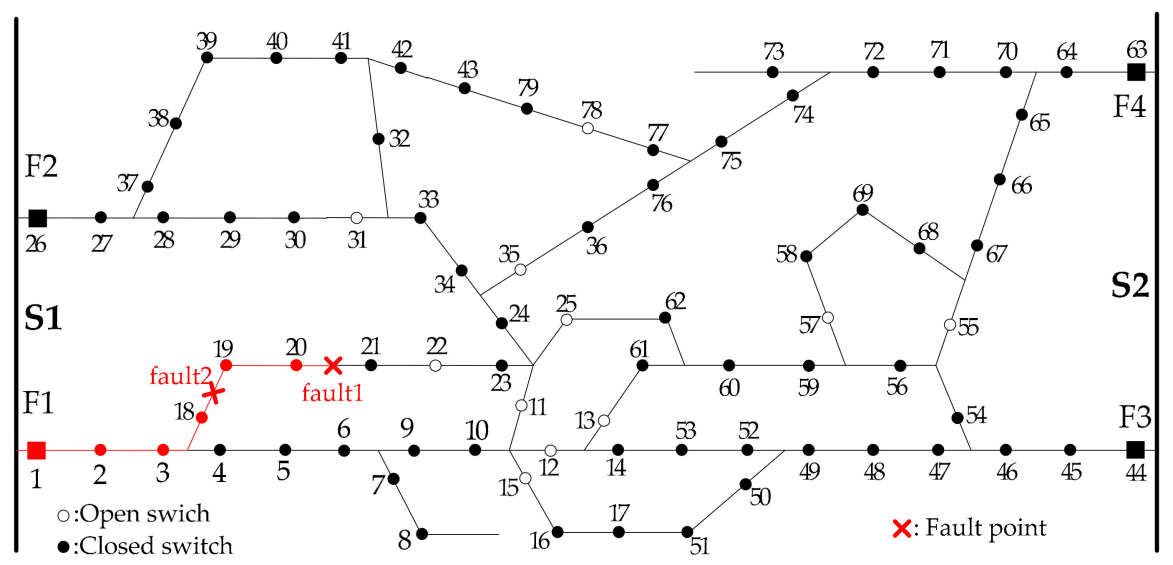

Figure 15. Simultaneous faults in the same lateral.

The state vector for this operating condition is:

$$
\begin{aligned}
\mathbf{s}= & {[11111111110001011111101101111101110111111} \\
& 11111111111110101111111111111111111101]^{\mathrm{T}}
\end{aligned}
$$

By applying the topology identification method, the faulted radial network can be recognized and expressed as:

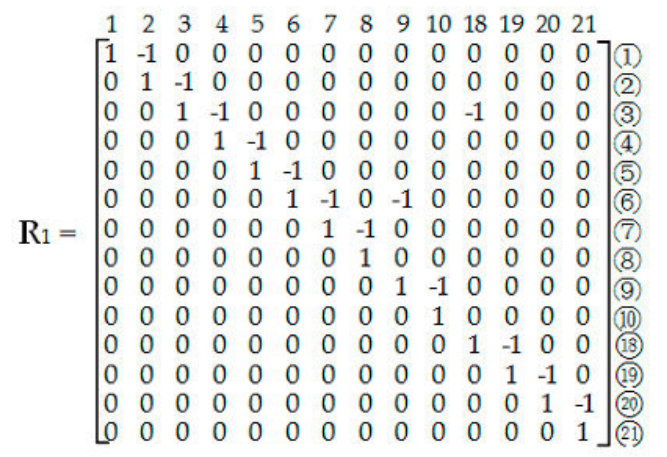

The fault information vector for this identified radial network is:

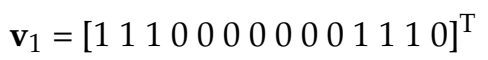

By substituting Equations (52) and (53) into Equation (16), the fault indication vector for this condition is calculated as:

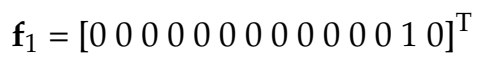

It can be seen from Equation (54) that the fault is located at section (20. After this fault is located, the isolation method will be triggered, and the fault will be isolated by opening Switches 20 and 21 . Then, the circuit breaker (Switch 1) at the very beginning of feeder F1 is closed to recover the power supply for the non-fault areas. However, due to the existence of "fault2", the proposed method will be started again. For this fault, the fault information vector is:

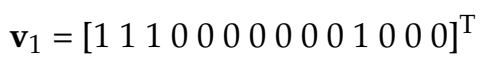


Then, the fault indication vector can be obtained by substituting Equations (52) and (55) into Equation (16).

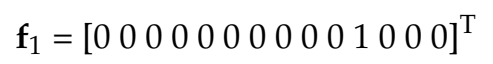

By applying the algorithm in Section 3.2 to the vector shown in (56), it is determined that another fault has occurred in section (18). It is the same as what is illustrated in Figure 15. The fault will be isolated by opening Switches 18 and 19.

By running the proposed algorithm twice, the two faults are located and isolated one by one. The results demonstrate the effectiveness of the method.

\subsection{Test Case 4: Fault Location and Isolation Considering Fault Information Loss}

In this case, the system operates under the same condition with that shown in Figure 14. The test fault is supposed to occur in feeder F4, which is illustrated in Figure 16. However, for some reasons, the fault information of Switches 72 and 75 is lost.

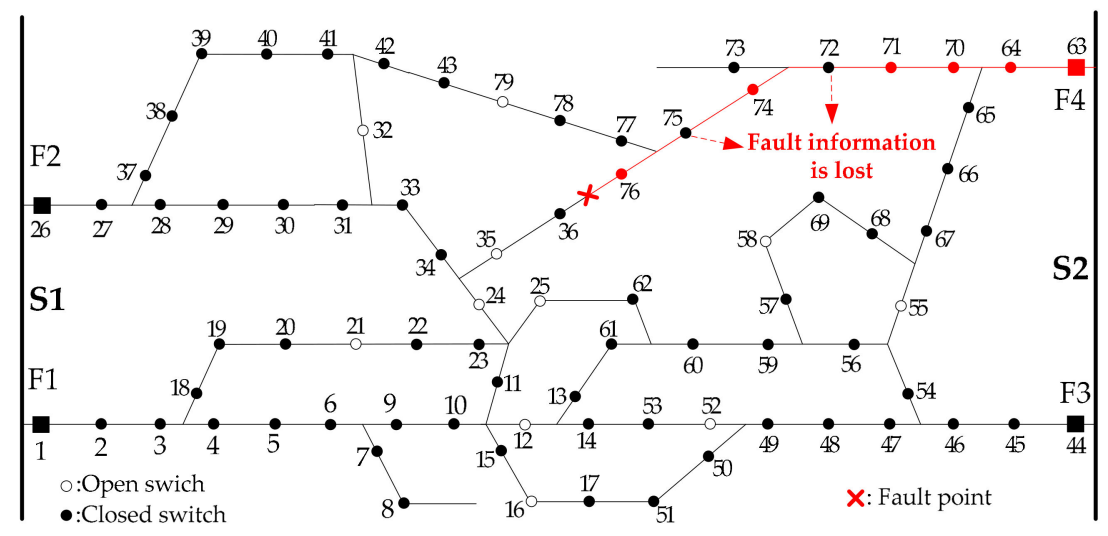

Figure 16. Fault with information loss.

By applying the topology identification method firstly, the faulted radial network can be recognized and expressed as:

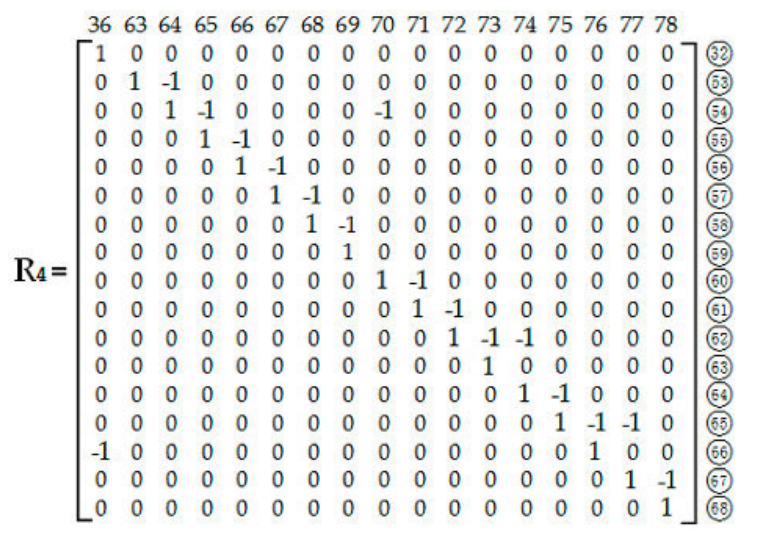

For this fault with information loss, the fault information vector is:

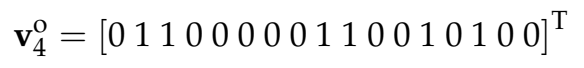

Without any correction of this vector, the following fault indicating vector will be derived:

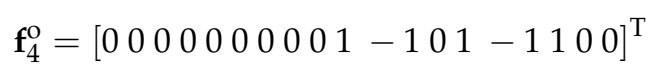


It can be seen from Equation (59) that five faulted feeder sections will be obtained, which does not agree with what is illustrated in Figure 16. Thus, to get an accurate result, the fault information vector must be corrected when there are fault information loss problems. By applying the modification technique proposed in [34] to the original $\mathbf{v}_{4}^{\mathbf{o}}$, the new fault information vector can be obtained as:

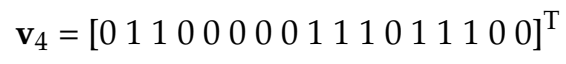

Substituting Equations (57) and (60) into Equation (16), the new fault indication vector will be calculated as:

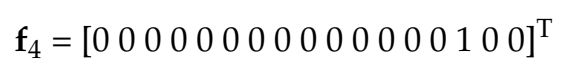

By applying the algorithm in Section 3.2 to the vector shown in Equation (61), it is determined that the fault has occurred in section (66). The result is the same as what is illustrated in Figure 16. The fault will be isolated by opening the switches of 36 and 76 .

\subsection{Comparison with Other Method}

There are various methods for fault location, such as impedance based methods, travelling-wave based methods, and voltage-sag based methods. Comparing to these methods, the proposed method has the following advantages:

(1) The proposed method can not only determine the faulted feeder section, but can also give the switches that should be opened to isolate the fault, which is cannot be done by the mentioned comparative methods.

(2) The propose method is not only applicable to single fault, but also to multiple simultaneous faults. The proposed method has no multiple-estimation problem.

(3) Comparing with the mentioned methods, the proposed algorithm does not use any physical or electrical parameters of the feeders. Thus, it is not affected by the fault type or fault/arc resistance, and it can be used on inhomogeneous feeders consisting of sections of both overhead line and underground cable.

\section{Conclusions}

This paper presents a novel method for locating and isolating faulted feeder sections on power distribution systems. In contrast to many other fault location methods that require prior knowledge of the exact network topology, the proposed algorithm continuously monitors the network configuration and automatically identifies the radial feeders of the network.

Since the data used by the algorithm are constantly updated, the algorithm automatically identifies and isolates the relevant feeder sections should a fault occur on the distribution system. As the algorithm does not use any physical or electrical parameters of the feeders, it is not affected by reconfigurations of the distribution system; it is not affected by the fault type or fault resistance; and it can be used on inhomogeneous feeders consisting of sections of both overhead line and underground cable. This represents a significant advance on the state of the art in distribution system fault location, which will help to improve the quality and security of the electricity supply.

Test cases demonstrated that the proposed algorithm can be used to accurately locate and isolate both single fault and multiple simultaneous faults.

Author Contributions: The paper was a collaborative effort between the authors. All authors have read and approved the final manuscript.

Conflicts of Interest: The authors declare no conflict of interest.

\section{Appendix A}

The appendix shows the network description matrix $\mathbf{M}_{\mathrm{o}}$ for the system illustrated in Figure 12. 


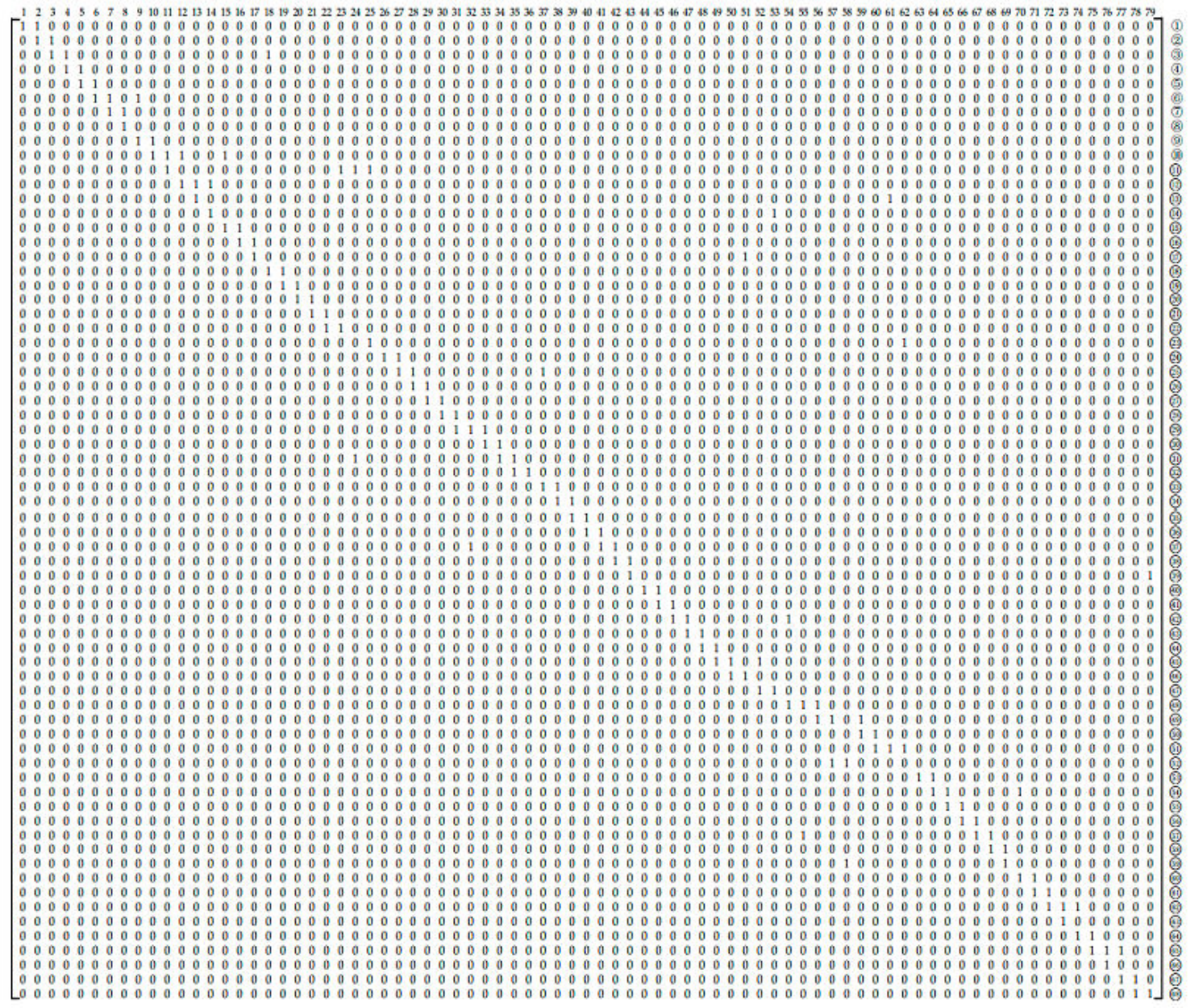

\section{References}

1. Mora, J.; Cormane, J.; Ordonez, G. K-means algorithm and mixture distributions for locating faults in power systems. Electr. Power Syst. Res. 2009, 79, 714-721. [CrossRef]

2. Institute of Electrical and Electronics Engineers. IEEE Guide for Determining Fault Location on AC Transmission and Distribution Lines; IEEE Std. C37.114-2004; IEEE: Piscataway, NJ, USA, 2005.

3. Salim, R.H.; Salim, K.C.O.; Bretas, A.S. Further improvements on impedance-based fault location for power distribution systems. IET Gen. Transm. Distrib. 2011, 5, 467-478. [CrossRef]

4. Personal, E.; García, A.; Parejo, A.; Larios, D.F.; Biscarri, F.; León, C. A comparison of impedance-based fault location methods for power underground distribution systems. Energies 2016, 9, 1022. [CrossRef]

5. Liao, Y. Generalized fault-location methods for overhead electric distribution systems. IEEE Trans. Power Del. 2011, 26, 53-64. [CrossRef]

6. Choi, M.S.; Lee, S.J.; Lim, S.I.; Lee, D.S.; Yang, X. A direct three-phase circuit analysis-based fault location for line-to-line fault. IEEE Trans. Power Del. 2007, 22, 2541-2547. [CrossRef]

7. Gabr, M.A.; Ibrahim, D.K.; Ahmed, E.S.; Gilany, M.I. A new impedance-based fault location scheme for overhead unbalanced radial distribution networks. Electr. Power Syst. Res. 2017, 142, 153-162. [CrossRef]

8. Gazzana, D.S.; Ferreira, G.D.; Bretas, A.S.; Carniato, A.; Passos, L.F.N.; Ferreira, A.H.; Silva, J.E.M. An integrated technique for fault location and section identification in distribution systems. Electr. Power Syst. Res. 2014, 115, 65-73. [CrossRef]

9. Hong, Y.Y.; Wei, Y.H.; Chang, Y.R.; Lee, Y.D.; Liu, P.W. Fault detection and location by static switches in microgrids using wavelet transform and adaptive network-based fuzzy inference system. Energies 2014, 7, 2658-2675. [CrossRef] 
10. Borghetti, A.; Corsi, S.; Nucci, C.A.; Paolone, M.; Peretto, L.; Tinarelli, R. On the use of continuous-wavelet transform for fault location in distribution power systems. Int. J. Electr. Power Energy Syst. 2006, 28, 608-617. [CrossRef]

11. Borghetti, A.; Boseti, M.; Di Silvestro, M.; Nucci, C.A.; Paolone, M. Continuous-wavelet transform for fault location in distribution power networks: Definition of mother wavelets inferred from fault originated transients. IEEE Trans. Power Syst. 2008, 23, 380-388. [CrossRef]

12. Orozco-Henao, C.; Bretas, A.S.; Chouhy-Leborgne, R.; Herrera-Orozco, A.R.; Marin-Quintero, J. Active distribution network fault location methodology: A minimum fault reactance and Fibonacci search approach. Int. J. Electr. Power Energy Syst. 2017, 84, 232-241. [CrossRef]

13. Grajales-Espinal, C.; Mora-Florez, J.; Perez-Londono, S. Advanced fault location strategy for modern power distribution systems based on phase and sequence components and the minimum fault reactance concept. Electr. Power Syst. Res. 2016, 140, 933-941. [CrossRef]

14. Mokhlis, H.; Haiyu, L.; Khalid, A.R. The application of voltage sags pattern to locate a faulted section in distribution network. Int. Rev. Electr. Eng. 2010, 5, 173-179.

15. Pereira, R.A.F.; da Silva, L.G.W.; Kezunovic, M.; Mantovani, J.R.S. Improved fault location on distribution feeders based on matching during-fault voltage sags. IEEE Trans. Power Del. 2009, 24, 852-862. [CrossRef]

16. Lotfifard, S.; Kezunovic, M.; Mousavi, M.J. Voltage sag data utilization for distribution fault location. IEEE Trans. Power Del. 2011, 26, 1239-1246. [CrossRef]

17. Mokhlis, H.; Li, H. Non-linear representation of voltage sag profiles for fault location in distribution networks. Int. J. Electr. Power Energy Syst. 2011, 33, 124-130. [CrossRef]

18. Jin, T.; Li, H. Fault location method for distribution lines with distributed generators based on a novel hybrid BPSOGA. IET Gen. Transm. Distrib. 2016, 10, 2454-2643. [CrossRef]

19. Salim, R.H.; de Oliveira, K.R.C.; Filomena, A.D.; Resener, M.; Bretas, A.S. Hybrid fault diagnosis scheme implementation for power distribution systems automation. IEEE Trans. Power Del. 2008, 23, 1846-1856. [CrossRef]

20. Aslan, Y.; Yagan, Y.E. Artificial neural-network-based fault location for power distribution lines using the frequency spectra of fault data. Electr. Eng. 2017, 99, 301-311. [CrossRef]

21. Zhabelova, G.; Vyatkin, V. Multiagent smart grid automation architecture based on IEC 61850/61499 intelligent logical nodes. IEEE Trans. Ind. Electron. 2012, 59, 2351-2362. [CrossRef]

22. Kashyap, N.; Yang, C.; Sierla, S.; Flikkema, P.G. Automated fault location and isolation in distribution grids with distribution control and unreliable communication. IEEE Trans. Ind. Electron. 2015, 62, 2612-2619. [CrossRef]

23. Ahuja, A.; Das, S.; Pahwa, A. An AIS-ACO hybrid approach for multi-objective distribution system reconfiguration. IEEE Trans. Power Syst. 2007, 22, 1101-1111. [CrossRef]

24. Teng, J.H.; Huang, W.H.; Luan, S.W. Automatic and fast faulted line-section location method for distribution systems based on fault indicators. IEEE Trans. Power Syst. 2014, 29, 1653-1662. [CrossRef]

25. Andrei, H.; Chicco, G. Identification of the radial configurations extracted from the weakly meshed structures of electrical distribution systems. IEEE Trans. Circuits Syst. I Reg. Pap. 2008, 55, 1149-1158. [CrossRef]

26. Sinngh, R.; Manitsas, E.; Pal, B.C.; Strbac, G. A recursive Bayesian approach for identification of network configuration changes in distribution system state estimation. IEEE Trans. Power Syst. 2010, 25, 1329-1336. [CrossRef]

27. Sharon, Y.; Annaswamy, A.M.; Motto, A.L.; Chakraborty, A. Topology identification in distribution network with limited measurements. Proceedings of 2012 IEEE Innovative Smart Grid Technologies Conference, Washington, DC, USA, 16-20 January 2012; pp. 1-6.

28. Zhao, L.; Song, W.Z.; Tong, L.; Wu, Y.; Yang, J. Topology identification in smart grid with limited measurements via convex optimization. In Proceedings of the 2014 IEEE Innovative Smart Grid Technologies-Asia, Kuala Lumpur, Malaysia, 20-23 May 2014; pp. 803-808.

29. Zorić, K.J.; Djurić, M.B.; Terzija, V. Arcing faults detection on overhead lines from the voltage signal. Int. J. Electr. Power Energy Syst. 1997, 19, 299-303. [CrossRef]

30. Alamuti, M.M.; Nouri, H.; Ciric, R.M.; Terzija, V. Intermittent fault location in distribution feeders. IEEE Trans. Power Del. 2012, 27, 96-103. [CrossRef]

31. Radojević, Z.; Terzija, V.; Djurić, M. Multipurpose overhead lines protection numerical algorithm. IEEE Proc. C 1999, 146, 441-446. 
32. Preston, G.; Radojević, Z.M.; Kim, C.H.; Terzija, V. New settings-free fault location algorithm based on synchronized sampling. IET Gen. Transm. Distrib. 2011, 5, 376-383. [CrossRef]

33. Terzija, V.V.; Koglin, H.J. Long arc in free air: Laboratory testing, modelling, simulation and model-parameters estimation. Generation, Transmission and Distribution. IEE Proc. 2002, 149, 319-325.

34. Sun, K.M.; Chen, Q.; Zhan, Z.J. An automatic faulted line section location method for electric power distribution systems based on multisource information. IEEE Trans. Power Del. 2016, 31, 1542-1551. [CrossRef]

35. Das, D. A fuzzy multiobjective approach for network reconfiguration of distribution systems. IEEE Trans. Power Del. 2006, 21, 202-209. [CrossRef]

36. Tomoiaga, B.; Chindris, M.; Sumper, A.; Villafafila-Robles, R.; Sudria-Andreu, A. Distribution system reconfiguration using genetic algorithm based on connected graphs. Electr. Power Syst. Res. 2013, 104, 216-225. [CrossRef]

(C) 2017 by the authors. Licensee MDPI, Basel, Switzerland. This article is an open access article distributed under the terms and conditions of the Creative Commons Attribution (CC BY) license (http://creativecommons.org/licenses/by/4.0/). 